\title{
Molecular analysis of the novel IDS allele in a Thai family with mucopolysaccharidosis type II: The c.928C $>$ T (p.Gln310*) transcript is sensitive to nonsense-mediated mRNA decay
}

\author{
LUKANA NGIWSARA $^{1}$, KITIWAN ROJNUEANGNIT ${ }^{2}$, DUANGRURDEE WATTANASIRICHAIGOON ${ }^{3}$, \\ THIPWIMOL TIM-AROON ${ }^{3}$, PHANNEE SAWANGAREETRAKUL ${ }^{1}$, VORARATT CHAMPATTANACHAI ${ }^{1}$, \\ JAMES R. KETUDAT-CAIRNS ${ }^{1,4}$ and JISNUSON SVASTI ${ }^{1}$
}

\author{
${ }^{1}$ Laboratory of Biochemistry, Chulaborn Research Institute, Bangkok 10210; ${ }^{2}$ Pediatrics Department, \\ Faculty of Medicine, Thammasat University, Bangkok 10200; ${ }^{3}$ Department of Pediatrics, Division of Medical Genetics, \\ Faculty of Medicine, Ramathibodi Hospital, Mahidol University, Bangkok 10400; ${ }^{4}$ School of Chemistry, \\ Institute of Science, Suranaree University of Technology, Nakhon Ratchasima 30000, Thailand
}

Received August 1, 2016; Accepted January 26, 2017

DOI: $10.3892 /$ etm.2017.4303

\begin{abstract}
Hunter syndrome (or mucopolysaccharidosis type II, MPS II) is an X-linked recessive disorder induced by a deficiency of the iduronate 2-sulfatase (IDS) enzyme, resulting in the accumulation of glycosaminoglycan substrates, heparan sulfate and dermatan sulfate, in the lysosomes. The progressive accumulation of undegraded metabolites induces cell and tissue dysfunction, leading to multi-systemic pathology. The heterogeneity of clinical phenotypes, ranging from mild to severe forms, results from different mutations in the IDS gene. To date, $>550$ MPS II causal mutations have been reported in the IDS gene, of which $\sim 10 \%$ are nonsense mutations that lead to premature protein termination. In the present study, the IDS mutation causing MPS II in an extended Thai family was identified using IDS enzyme assay and IDS gene exon sequencing. Three family members were enzymatically confirmed to have MPS II and to carry the novel IDS nonsense allele c.928C $>$ T (p.Gln310*). The IDS mRNA levels were evaluated by reverse transcription-quantitative polymerase chain reaction, which demonstrated that all patients exhibited a reduction of IDS mRNA, suggesting its degradation by nonsense-mediated mRNA decay. Expression of wild type and mutant IDS in COS-7 cells revealed that the IDS p.Gln310* mutant lacked
\end{abstract}

Correspondence to: Professor Jisnuson Svasti, Laboratory of Biochemistry, Chulabhorn Research Institute, 54 Kamphaeng Phet 6 Road, Talat Bang Khen, Lak Si, Bangkok 10210, Thailand E-mail: jisnuson@cri.or.th

Abbreviations: MPS II, mucopolysaccharidosis type II; IDS, iduronate 2-sulfatase; RT-qPCR, reverse transcription-quantitative polymerase chain reaction; NMD, nonsense-mediated mRNA decay

Key words: mucopolysaccharidosis type II, iduronate 2-sulfatase, nonsense mediated mRNA decay
IDS activity, consistent with production of a nonfunctional, prematurely truncated protein. Taken together, these results indicate that the IDS c.928C $>$ T (p.Gln310*) mutation is a severe disease-causing mutation for MPS II.

\section{Introduction}

Hunter syndrome, which is also known as mucopolysaccharidosis type II (MPS II; OMIM \#309900) is a rare, X-linked recessive disorder caused by a deficiency of the lysosomal enzyme iduronate 2-sulfatase (IDS; EC 3.1.6.13) (1). IDS acts in the catabolism of heparan sulfate and dermatan sulfate, and defects in the enzyme lead to systemic accumulation and increased excretion of these mucopolysaccharides in the urine (2). MPS II has a broad spectrum of clinical phenotypes ranging from mild to severe forms. The severe phenotype or early progressive form is characterized by short stature, facial dysmorphism, bone abnormalities, hepatosplenomegaly, mental retardation, heart valve disease and mortality in the second decade of life, whereas the most mild or attenuated form exhibits no association with the central nervous system and a near normal life expectancy of 50-60 years (3).

MPS II has an incidence of $\sim 0.3-0.71$ in 100,000 live births (4). The prognosis is very serious in MPS II and no curative therapy is currently available. Enzyme replacement therapy (ERT) and bone marrow transplantation (BMT) are the two current therapeutic approaches available for MPS II (5). The evidence supporting both therapies remains limited: It has been demonstrated that ERT with iduronate sulfatase is effective in relation to functional capacity (distance walked in six min and forced vital capacity), liver and spleen volumes and urine glycosaminoglycan excretion (6). To the best of out knowledge, there is no evidence available regarding the outcomes, such as improvement in growth, sleep apnoea, cardiac function, quality of life and mortality. Furthermore, iduronate sulfatase therapy is extremely expensive and must be continued to maintain its benefits. Trials of haematopoietic stem cell transplantation have had mixed results with 
evidence of biochemical/dermatological amelioration which does not necessarily translate into clinical improvement $(7,8)$. Alternative approaches may become available depending on the mutation effect, for instance, nonsense mutations may be rescued by ribosomal read-through induced by small molecules that increase read-through at these premature stop signals to enable the production of full-length proteins (9). Classic gene therapy using a retroviral vector may still offer future hope of yielding a definitive treatment (10). However, a number of challenges remain and more basic knowledge on the molecular basis of the disease is required to improve effective therapy.

The human IDS gene spans $24 \mathrm{~kb}$ on chromosome Xq28 and contains nine exons (1). The open reading frame is $1,653 \mathrm{bp}$ encoding a polypeptide of 550 amino acids. A pseudogene is located $\sim 25 \mathrm{~kb}$ telomeric to the functional gene, with regions homologous to IDS exons 2 and 3 and IDS introns 2, 3 and 7, and this pseudogene appears to be responsible for increasing susceptibility to various types of complex recombination events (11-13). According to the Human Genome Mutation Database (14), >550 different mutations causing MPS II have been characterized; including $>280$ missense and nonsense mutations.

IDS mutation heterogeneity in the Thai population has previously been described by the current authors $(15,16)$. A total of 21 different mutations, including 9 missense, 3 nonsense, 3 splice site alterations, 1 deletion, 2 indels, and 1 rearrangement, were identified, 10 of which were novel (p.R101C, p.D148V, p.G224A, p.K227E, p.E254X, p.W337X, p.R88C, p'Y348X, c.440_442delinsTT and c.720_731delinsTTTCAGA TGTTCTCCCCAG). In the present study, a novel IDS allele [c.928C >T; (p.Gln310*)] was identified, which is associated with early progressive MPS II. The impact of the mutation was analyzed via its expression in the COS-7 cell line.

\section{Materials and methods}

Patients and MPS II diagnosis. Patient P1 presented at Thammasat University Hospital, at 2 years of age for recurrent upper respiratory tract infection, and was noted to have generalized overgrowth. Developmental delay and attention deficit, facial coarsening, claw hands, generalized joint stiffness and mild hepatosplenomegaly became evident at the age of 3. Analysis of leukocyte enzyme activity confirmed Mucopolysaccharidosis type II (MPS II). At the age of 7, the patients development was equivalent to 3-4 years of age, as evaluated by the Mullen Scale of Early Learning (17).

Patient P2 presented to Ramathibodi Hospital at the age of 3 for declining speech and psychomotor skill over the preceding year. Review of medical history indicated overgrowth since 6 months of age, snoring, and hyperactivity. Physical examination revealed storage phenotypes, suggesting MPS II. The patients echocardiogram indicated a thickening of the mitral and aortic valve, mitral valve prolapse and mild mitral regurgitation with left ventricular ejection fraction (LVEF) of $67 \%$.

Patient P3, at the age of 1 years and 7 months, accompanied an older brother (patient P2) to the hospital. The patient was noted to have overgrowth, mild facial coarsening, joint stiffness and an umbilical hernia. Therefore, leukocyte enzyme analysis for MPS II were recommended and confirmed the disorder. Subsequently, slow psychomotor regression was reported. There was thickening of mitral and aortic valve with LVEF of $61 \%$, as demonstrated by echocardiogram.

The family history of $\mathrm{P} 2$ and $\mathrm{P} 3$ revealed multiple affected males in older generations and suggested their relation to P1 (Fig. 1); therefore, the three patients and their relatives were invited to participate in genetic analysis, when $\mathrm{P} 1, \mathrm{P} 2$, and $\mathrm{P} 3$ were 7, 4, and 3 years old, in respective order. Written informed consents were obtained from each participant following the protocol approved by the Ramathibodi Hospital Institutional Review Board. Written informed consent forms were obtained from all the participants. The study was conducted following the protocol approved by the Ramathibodi Hospital Institutional Review Board (protocol ID 01-51-14).

Leukocyte preparation. Blood samples were collected from patients, their parents, and unaffected relatives. The blood samples were collected into BD Vacutainer ${ }^{\mathrm{TM}}$ Plastic Blood Collection Tubes with K2EDTA (BD Biosciences, Franklin Lakes, NJ, USA) and mixed promptly to avoid sample clotting, for the 3 patients, their parents and unaffected relatives and used for leukocyte preparation. Briefly, $15 \mathrm{ml}$ of buffer EL (Qiagen GmbH, Hilden, Germany) was added into $3 \mathrm{ml}$ of blood samples (ratio of 5:1). The mixture was incubated on ice for $15 \mathrm{~min}$ to lyse red blood cells. The mixture was centrifuged at $400 \mathrm{x} g$ for $10 \mathrm{~min}$ at $4^{\circ} \mathrm{C}$. The supernatant was removed and washed with buffer EL until the white blood cells turned white (2-3 times). The white cell pellets were further washed with $0.9 \% \mathrm{NaCl}$ and centrifuged at $400 \mathrm{x} g$ for $10 \mathrm{~min}$ at $4^{\circ} \mathrm{C}$. Finally, the pellet was resuspended in $200 \mu \mathrm{l}$ $0.9 \% \mathrm{NaCl}$ with $2 \mu \mathrm{l} 100 \mathrm{mM}$ phenylmethylsulfonyl fluoride (PMSF; Sigma-Aldrich; Merck KGaG, Darmstadt, Germany) and sonicated at $30 \%$ output, pulse on-off $5 \mathrm{sec}$ for a total of $20 \mathrm{sec}$ (U200H control sonicator; IKA Labortechnik, Staufen, Germany). The lysed cells were processed for the enzyme assay and protein determination.

Enzyme assay. IDS activity was measured via the hydrolysis of 4-methylumbelliferyl- $\alpha$-iduronide-2-sulfate (4-MU; Moscerdam Substrates, Oegstgeest, The Netherlands) in homogenates of leukocytes and transfected COS-7 cells (see below), as previously described (18). The IDS activities from 23 unaffected Thai controls were obtained from collecting samples between February 2010 and January 2016, in the Ramathibodi Hospital. An inclusion criterion for the study was that the history family of all participants is not effected by MPS II. All participants signed an informed consent prior to their participation. They comprised 15 males, aged 11-32 years and 8 females, aged 15-30 years.

Genomic DNA and complementary DNA analysis of the IDS gene. Genomic DNA was isolated from leukocytes with the QIAamp DNA Mini kit (QIAGEN GmbH). Total RNA preparation and cDNA synthesis were performed as previously described (15). IDS gene exons and flanking splicing-sites were amplified with the following primers: IDS Exon 1: 5'-GCAGTGGCTGAATCGCTATACC-3' and IDSR1: 5'-GGATGAAAGAAGGAATGGTAGGAGAG-3', exon 2; IDSF2: 5'-GAGGGAGGGTTCAGTGTCAGTG-3' and IDSR2: 5'-CCATCTGACAATAGCTGAAGCTCC-3', 
exon 3; IDSF3: 5'-GCGGTTGCTTGGTTACCTAAGAG-3' and IDSR3: 5'-TACCACCCGAGGAGCTGAAAG-3', exon 4; IDSF4: 5'-CTAGAGAGTTTGGCTTTAGAGGGGAC-3' and IDSR4: 5'-CGTGAGCACTGGGGAGCTATT C-3', exon 5; IDSF5: 5'-GTGTGTGTAGCCTTCATGGCTTC-3' and IDSR5: 5'-GATTCTTACATGTTCTTGGCCTTGAC-3', exon 6; IDSF6: 5'-CATCCCAGGCTTAGAGGAAAGG-3' and IDSR6: 5'-CTGAGAAGAGTGGTTTCACCTACG AC-3', exon 7; IDSF7: 5'-CATCAACTAAGGGGTAGG GATTGG-3' and IDSR7: 5'-CAGGATCCCACTTTGTTT GTGAAC-3', exon 8; IDSF8: 5'-CCGCCACAGAGTCCT ACGTTAG-3' and IDSR8: 5'-GAAGGGGGGGTCTGT GTAACC-3', exon 9; IDSF9: 5'-ACAGGTTCCTTTACT GCTCCTGC-3' and IDSR9: 5'-GAAATCCCATGGTCT TAGAAACAAAAG-3'. The amplified products were sent for direct Sanger sequencing at Macrogen, Inc. (Seoul, Korea). The mutation identified was verified to not occur in unaffected control $\mathrm{X}$ chromosomes by Sanger sequencing of the IDS exon 7 of 100 healthy controls by Macrogen, Inc. (Seoul, Korea). The IDS sequence was then detected using GeneBank (https://www.ncbi.nlm.nih.gov/genbank/), Clustalx (http://www.clustal.org/clustal2/) and BioEdit (http://www.mbio.ncsu.edu/BioEdit/page2.html).

Reverse transcription-quantitative polymerase chain reaction (RT-qPCR) analysis. Primers were designed to yield a product of $100 \mathrm{bp}$, specific to exons 4 and 5 . The ribosomal protein S13 (RPS13) gene was used as a reference gene. The primer sequences for IDS and the RPSI3 gene were as follows: IDS, forward 5'-GGAACATCCAGCACATCCAC-3', and reverse 5'-GGAACATCCAGCACATCCAC-3'; and RPS13, forward 5'-CGAAAGCATCTTGAGAGGAACA-3', and reverse 5'-TCGAGCCAAACGGTGAATC-3'. Each PCR reaction $(20 \mu \mathrm{l})$ was composed of $10 \mu 1$ KAPA SYBR FAST qPCR kit Master mix (Kapa Biosystems, Inc., Wilmington, MA, USA), $1 \mu 15$-fold diluted cDNA and 10 pmol PCR primers. qPCR was performed using StepOnePlus Real-Time PCR System (Applied Biosystems; Thermo Fisher Scientific, Inc., Waltham, MA, USA). The PCR conditions were as follows: An initial activation step at $95^{\circ} \mathrm{C}$ for $10 \mathrm{~min}$, followed by 40 cycles of denaturation at $95^{\circ} \mathrm{C}$ for $30 \mathrm{sec}$, annealing at $58^{\circ} \mathrm{C}$ for $30 \mathrm{sec}$ and extension at $72^{\circ} \mathrm{C}$ for $30 \mathrm{sec}$. Detection data were analyzed using the $2^{-\Delta \Delta \mathrm{Cq}}$ method (19). The ratios of gene expression values were normalized using that of RPS13 (as internal control). Melting curve analysis was used to validate the reactions. The relative mRNA expression of the IDS gene was normalized to the level of RPS13 mRNA. All statistical data were compiled from $\geq 3$ independent experiments. Data are expressed as mean \pm standard deviation, which was analyzed by using SPSS version 12.0 for Windows (SPSS, Inc., Chicago, IL, USA). The PCR products were analyzed by $1.2 \%$ agarose gel electrophoresis, stained in $0.5 \mu \mathrm{g} / \mathrm{ml}$ ethidium bromide solution and visualized by UV transilluminator (Gene Genius, Bio Imaging System). Normal controls ( $\mathrm{n}=10)$ were used for RT-qPCR analysis, collected between January 2015 and January 2016, in the Ramathibodi Hospital. All participants signed an informed consent prior to their participation. The patients comprised 5 males, aged 22-30 years and 5 females, aged 20-30 years.
Construction of IDS mutants and expression in COS-7 cells. The full-length IDS cDNA of the normal healthy control and P1 were PCR-amplified with the following cDNA primers: Forward: 5'-CGACGAGGAGGTCTCTGTG-3' and reverse: 5'-CAACTGGAAAAGATCTCC-3'; and cloned into the pcDNA3.1/CT-GFP-TOPO plasmid (Invitrogen; Thermo Fisher Scientific, Inc.). PCR was performed in an Applied Biosystems Veriti ${ }^{\mathrm{TM}}$ Thermal Cycler (Applied Biosystems; Thermo Fisher Scientific, Inc., Waltham, Ma, USA) with the aforementioned primers. PCR was carried out for 30 cycles with an initial denaturation at $94^{\circ} \mathrm{C}$ for $5 \mathrm{~min}$, cycles of denaturation at $94^{\circ} \mathrm{C}$ for $30 \mathrm{sec}$, annealing at $55^{\circ} \mathrm{C}$ for $1 \mathrm{~min}$ and extension at $72^{\circ} \mathrm{C}$ for 2.5 min with a final extension for $5 \mathrm{~min}$. The reaction mixture $(25 \mu \mathrm{l})$ contained $50 \mathrm{ng}$ DNA template, $1 \mathrm{X}$ PCR buffer containing $1.5 \mathrm{mM} \mathrm{MgCl} 2$, $2 \mathrm{mM}$ each dNTP, 10 pmol each primer and 1 Unit of High Fidelity PCR Enzyme Mix (Thermo Fisher Scientific, Inc.). The constructs were verified by direct DNA sequencing. COS-7 cells were obtained from the American Type Culture Collection (ATCC, Rockville, MD, USA). A total of $3 \times 10^{5}$ COS-7 cells were seeded on a 6 well plate in $2 \mathrm{ml}$ of Dulbeccos' modified Eagle's medium (Gibco; Thermo Fisher Scientific, Inc., Waltham, MA, USA) $24 \mathrm{~h}$ prior to transfection. Cells in culture plates were transfected with $4 \mu \mathrm{g}$ wild-type or mutant constructs with Lipofectamine 2000 Transfection Reagent (Invitrogen; Thermo Fisher Scientific, Inc.) according to the supplier's protocol. Following $24 \mathrm{~h}$ of incubation, at $37^{\circ} \mathrm{C}$, cells were scraped and resuspended in $1 \mathrm{ml}$ phosphate-buffered saline (PBS) and washed with the same buffer 2 times by centrifugation at $400 \mathrm{x} g$ for $10 \mathrm{~min}$, at $4^{\circ} \mathrm{C}$. Cells were resuspended in $200 \mu 1 \mathrm{PBS}$ to a concentration of $\sim 3 \times 10^{6}$ cells $/ \mathrm{ml}$ and were used for western blot analysis and IDS activity measurement following $24 \mathrm{~h}$. These experiments were performed in triplicate. The previously described plasmid pcDNA3.1/CT harboring the p.Tyr348* mutant (16) was used as a positive control of a truncated protein.

Western blot analysis. To lyse cells for analysis, $200 \mu \mathrm{l}$ cell suspension $\left(3 \times 10^{6}\right.$ cells $\left./ \mathrm{ml}\right)$ was mixed with $2 \mu 1100 \mathrm{mM}$ PMSF and sonicated at 30\% output, pulse on-off $5 \mathrm{sec}$, for a total of $20 \mathrm{sec}$. The lysed cells were processed for the enzyme assay and protein determination. Following the lysis of leukocyte and transfected COS-7 cell samples, the protein concentration was determined with the Bio-Rad protein assay (Bio-Rad Laboratories, Inc., Hercules, CA, USA). A total of $10 \mu \mathrm{g}$ protein from cell lysates of the transfected COS-7 cells was loaded in each lane, separated by $10 \%$ SDS-PAGE and electrotransferred onto PVDF membranes (FluoroTrans; Pall Corporation, Port Washington, NY, USA). Following blocking with $10 \%$ non-fat dry milk for $1 \mathrm{~h}$ at room temperature, membranes were incubated with the primary antibody, mouse monoclonal anti-human IDS antibody (dilution 1:2,000; \#2449; R\&D Systems, Inc.) at $4^{\circ} \mathrm{C}$ overnight. Membranes were subsequently washed 3 times for $10 \mathrm{~min}$ with Tris-buffered saline containing $0.1 \%$ Tween 20 (TBST) and then incubated with secondary antibody, polyclonal rabbit anti-mouse immunoglobulin conjugated with horseradish peroxidase (dilution 1:5,000; \#P0260; Dako; Agilent Technologies, Inc., Santa Clara, CA, USA), at room temperature for $1 \mathrm{~h}$. Following washing with TBST 3 times for $10 \mathrm{~min}$, membranes were 
Table I. Patient phenotypes, genotype and IDS activity.

\begin{tabular}{llcc}
\hline Patient/control & \multicolumn{1}{c}{ Phenotype } & Genotype & $\begin{array}{c}\text { IDS activity (nmol } \\
\text { 4-MU/4 h/mg protein) }\end{array}$ \\
\hline P1 & Affected & p.Gln310*/- & $\mathbf{0 . 7 2 0}$ \\
Mother of P1 & Unaffected carrier & p.Gln310*/wt & 20.6 \\
Father of P1 & Unaffected & $\mathrm{Wt}$ & 40.8 \\
Brother of P1 & Unaffected & $\mathrm{Wt}$ & 34.4 \\
Sister of P1 & Unaffected & $\mathrm{Wt}$ & 30.9 \\
P2 & Affected & p.Gln310*/- & $\mathbf{0 . 1 4 5}$ \\
P3 & Affected & p.Gln310*/- & $\mathbf{0 . 0 3 0}$ \\
Mother of P2 and P3 & Unaffected carrier & p.Gln310*/wt & 19.0 \\
Father of P2 and P3 & Unaffected & Wt & 30.0
\end{tabular}

Unaffected Thai controls ( $\mathrm{n}=23$ ) indicate a range for IDS activity of $26-55 \mathrm{nmol} 4-\mathrm{MU} / 4 \mathrm{~h} / \mathrm{mg}$ protein, with mean of $33.9 \pm 9.03 \mathrm{nmol} / 4 \mathrm{~h} / \mathrm{mg}$. IDS, iduronate 2-sulfatase; 4-MU, 4-methylumbelliferyl- $\alpha$-iduronide-2-sulfate; P, patient; wt, wild type. Bold letters indicate the IDS activity in the patients.

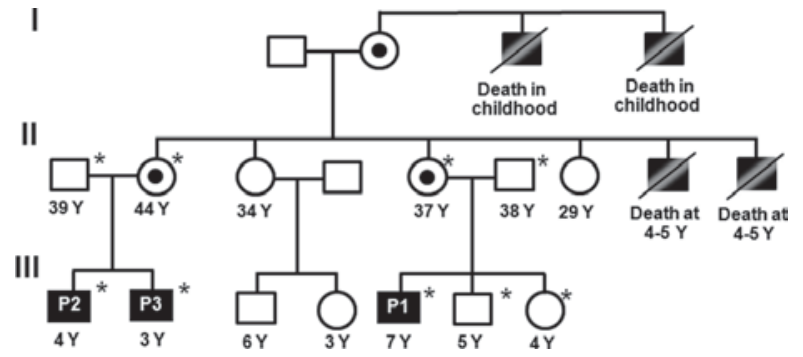

Figure 1. Three generations (I, II and III) of an extended family with Hunter syndrome. Squares and circles indicate males and females, respectively. Black square symbols indicate patients (P1, P2 and P3). Circled dot symbols indicate carriers. "Mutation analysis and iduronate 2-sulfatase activity measurement were performed. Y, years.

visualized via chemiluminescence using WesternBright electrochemiluminescence reagents (Advansta Inc., Menlo Park, CA, USA). Mouse monoclonal anti-human- $\beta$-actin antibody (dilution 1:20,000; \#3700; Cell Signaling Technology, Inc.) was used as a protein loading control.

Molecular modeling of IDS. A model of the IDS protein was built using the Swiss-Model homology modeling server (swissmodel.expasy.org) (20), which was used to construct a three-dimensional structural model of IDS with human arylsulfatase B (N-acetylgalactosamine-4-sulfatase; PDB code: 1FSU) as the template (21). Pymol version 1.7 (Schrödinger, Inc., New York, NY, USA.) was used to display the structural features of IDS.

Statistical analysis. Differences between the IDS mRNA expression of patients and control group and differences between the wild-type enzyme activity and the mutant p.Gln310* activity were analyzed by the Student's t-test (two-tailed) with SPSS version 12.0 for Windows (SPSS, Inc., Chicago, IL, USA). $\mathrm{P}<0.05$ was considered to indicate a statistically significant difference. Data is presented as mean \pm standard deviation.
A

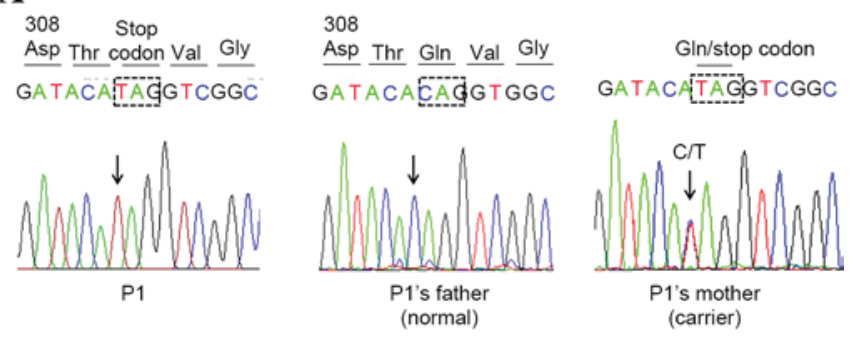

B

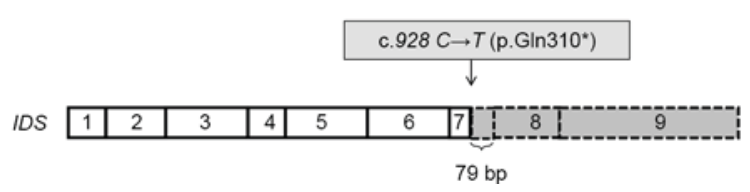

Figure 2. Sequencing chromatograms and schematic diagram of c.928C $>\mathrm{T}$ (p.Gln310*) mutation. (A) DNA sequencing revealed hemizygous T allele or [c.928C $\left.>\mathrm{T}\left(\mathrm{p} . \mathrm{Gln} 310^{*}\right)\right]$ mutation in P1, wild-type $\mathrm{C}$ allele in his father who served as a normal control, and both $\mathrm{C}$ and $\mathrm{T}$ alleles in the mother, which confirmed her carrier status. (B) Schematic diagram showing the mutation position at 79 nucleotides upstream from the exon 7 -exon 8 junction point, resulting in loss of the C-terminal 240 amino acid residues. P1, patient 1; IDS, iduronate 2-sulfatase.

\section{Results}

Clinical and biochemical analysis of MPS II patients. The range of the IDS enzyme activities in leukocyte extracts of the patients $(0.03-0.70 \mathrm{nmol} 4-\mathrm{MU} / 4 \mathrm{~h} / \mathrm{mg}$ protein) was $0.08-2.06 \%$ of the mean IDS activity of unaffected Thai controls $(33.9 \pm 9.03 \mathrm{nmol} / 4 \mathrm{~h} / \mathrm{mg}, \mathrm{n}=23)$, as presented in Table I, thereby suggesting a serious defect in the IDS enzyme.

Mutation analysis of IDS gene. Sequencing of all nine exons and surrounding introns of $\mathrm{P} 1, \mathrm{P} 2$ and $\mathrm{P} 3$ revealed only a nonsense mutation c. $928 \mathrm{C}>\mathrm{T}$ located on exon 7 of the IDS gene, resulting in a premature termination of polypeptide synthesis at position 310, designated as p.Gln310* (Fig. 2). The mother of P1 and the mother of P2 and P3 were confirmed 

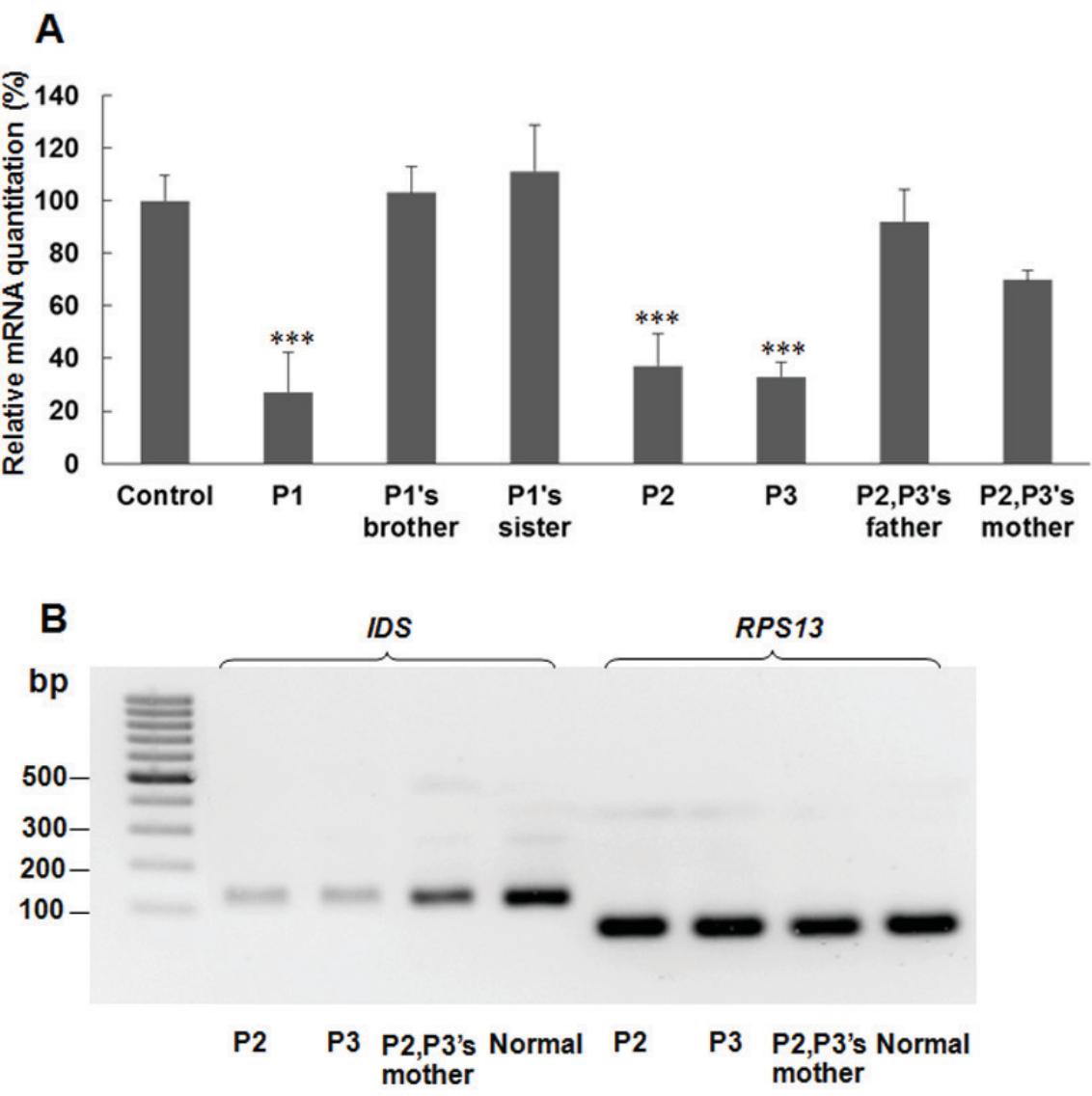

Figure 3. Analysis of IDS mRNA expression. (A) Relative IDS mRNA level in leukocytes of patients and family members, analyzed by the $2^{-\Delta \Delta C q}$ method. The control levels were from 10 different normal males. Data are presented as the mean \pm standard deviation. The RT-qPCR products from P1, P2 and P3 demonstrated decreased IDS mRNA expression compared with the mean IDS mRNA expression of 10 controls. ${ }^{* * *} \mathrm{P}<0.001$ vs. control group. (B) Agarose gel electrophoresis of the RT-qPCR products of IDS from P2, P3 and their relatives compared with a healthy control. RPS13 was used as a reference gene. IDS, iduronate 2-sulfatase; RT-qPCR, reverse transcription-quantitative polymerase chain reaction; P, patient; RPS13, ribosomal protein S13.

to be carriers while the remaining family members had the wild-type allele and unaffected phenotype (Fig. 1 and Table I). This variant was not observed in 100 healthy control chromosomes of unaffected Thai individuals.

Impact of c.928C $>T$ (p.Gln310*) mutation on $m R N A$ expression. The consequence of the c.928C $>\mathrm{T}$ (p.Gln310*) mutation was tested by RNA analysis. As premature termination codons are typically associated with an allele-specific reduction in mRNA levels, the role of nonsense-mediated mRNA decay (NMD) (22) in the pathogenesis of p.Gln310* was investigated. mRNA transcript levels were evaluated by RT-qPCR. The relative IDS mRNA transcript levels for patients P1, P2 and P3 were 27.2, 37.1 and 33.0\% respectively, compared with the mean IDS mRNA expression of 10 controls, indicating significantly lower expression $(\mathrm{P}<0.001$; Fig. 3A). In addition, representative transcription products of $\mathrm{P} 2$ and $\mathrm{P} 3$ were visualized by agarose gel electrophoresis, as described in the methods section, demonstrating lower amounts of the product band in P2 and P3 compared with a healthy control (Fig. 3B).

p.Gln310* expression in COS-7 cells. IDS processing appears to be identical among human fibroblasts, human lymphoblastoid cell lines and COS-7 cells (23). Thus, expression of the p.Gln310* mutant in COS-7 cells was studied, and compared with that of the wild type and the known p.Tyr348* mutant. Western blot analysis demonstrated that the wild-type IDS exhibited the expected band pattern of a 75-78-kDa precursor, and 55 and $45 \mathrm{kDa}$ mature polypeptides (Fig. 4A). The previously reported mutant, p.Tyr348*, which induces early termination of protein synthesis (16), migrated at an apparent molecular mass of $50 \mathrm{kDa}$. However, the p.Gln310* mutant, which encodes a truncated protein missing the $240 \mathrm{C}$-terminal amino acid residues, exhibited two bands in the molecular mass range of 40-45 kDa, which may be due to the differentially glycosylated or proteolytically processed forms of the truncated IDS. The shortened polypeptide chain p.Gln310* also appeared to cause destabilization of the protein structure, as lower amounts were observed in comparison to those of the wild type and $\mathrm{p}$. Tyr348* mutant.

Measurement of enzyme activity in COS-7 cell extracts indicated that the IDS with the p.Gln310* mutation had almost no activity $(0.97 \%$ of the wild-type activity; indicating significantly lower expression $(\mathrm{P}<0.001$; Fig. 4B). At present, the crystal structure of human IDS has not been reported. Of the 17 sulfatase gene family proteins found in humans, the crystal structures of human arylsulfatase A (24), human arylsulfatase B (N-acetylgalactosamine-4-sulfatase; ASB) (21), and human placental estrone/dehydroepiandrosterone sulfatase (aryl sulfatase C (25) have been elucidated. As all human sulfatases 

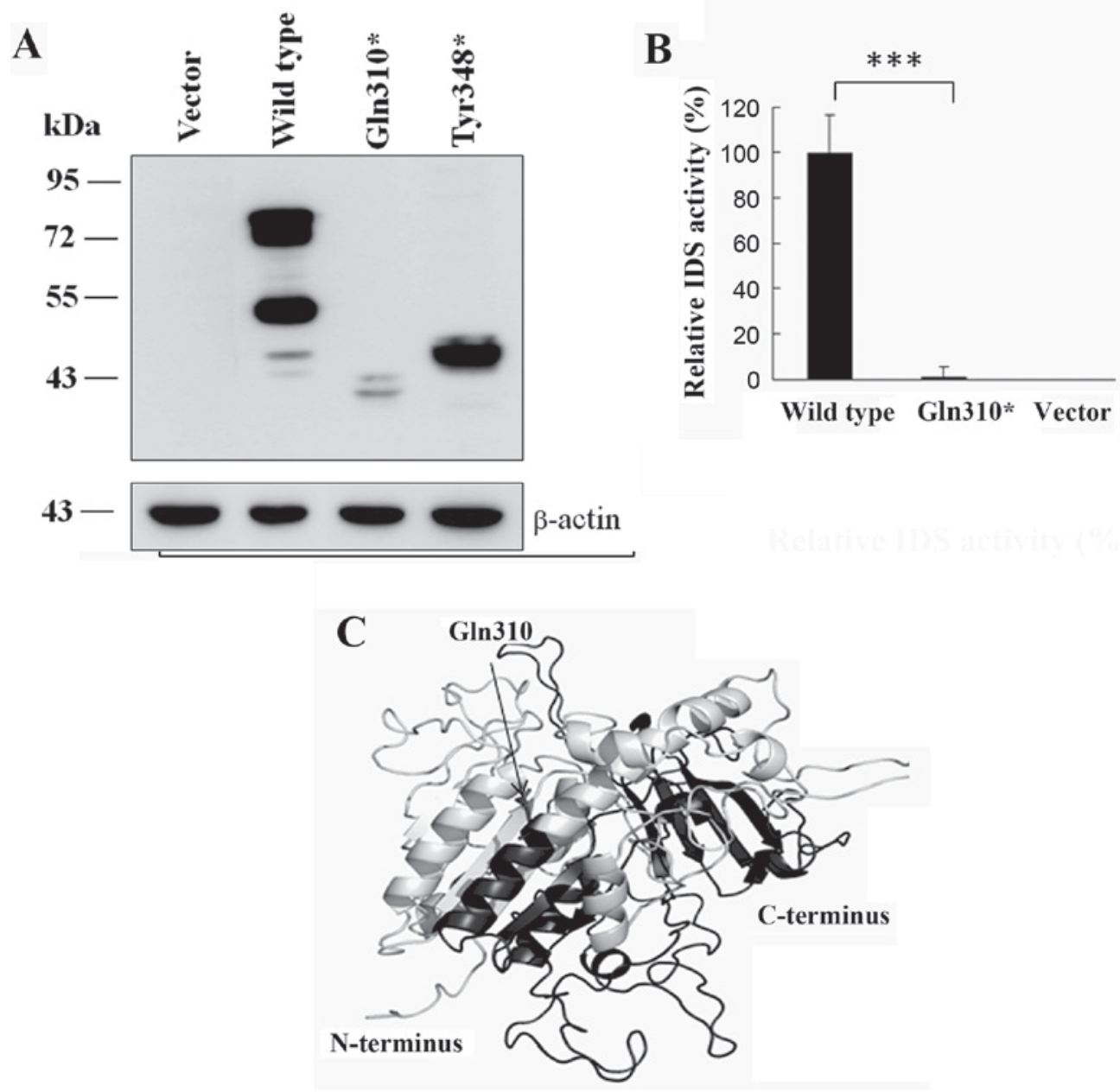

Figure 4. COS-7 expression analysis and IDS homology model. (A) Western blot analysis of IDS protein in the wild type and truncated mutants (p.Gln310* and p.Tyr348*), using $\beta$-actin as a loading control. (B) IDS activity in COS-7 cells transiently transfected with the wild type and p.Gln310* mutant was measured using a fluorogenic substrate, 4-methylumbelliferyl- $\alpha$-IDS. Values are expressed as the mean \pm standard deviation of the percentage of wild type enzyme activity. ${ }^{* * *} \mathrm{P}<0.001$ vs. wild type. (C) Location of the p.Gln310* mutation on a 3D homology model. The position of the mutation is indicated by the stick residue, light and dark gray represent the remaining and deleted amino acid residues in the mutant protein, respectively. IDS, iduronate 2-sulfatase.

exhibit a similar catalytic domain structure (26), modeling was attempted with each of the related sulfatases; however, only the use of ASB as a template produced a full catalytic domain model of IDS (Fig. 4C). p.Gln310* is located in the middle of a long $\alpha$-helix in the highly conserved sulfatase catalytic domain, which spans amino acid residues 33-420 (27); therefore it leads to loss of the substrate binding pocket, which is consistent with the lack of enzyme activity in transfected COS-7 cells.

\section{Discussion}

To date, $>550$ different mutations associated with MPS II have been identified (14). Of the mutations reported, $\sim 60 \%$ are point mutations (missense, $43 \%$; nonsense, 10\%; splice site alterations, 9\%) (14). Small insertion/deletions account for $30 \%$ of the total mutations and the remainder are gross deletions/insertions resulting from small chromosomal structural aberrations, accounting for $\sim 11 \%$ of MPS II cases (14). Genotype-phenotype correlation is not evident, with the exception of the c.1122C $>\mathrm{T}$ (splice site mutation) being associated with slowly progressive phenotype and gene deletion, or complex rearrangement associated with early progressive CNS manifestation $(28,29)$. However, in the present study, the presence of a nonsense mutation seems to be consistent with the observed early progressive type of MPS II.

In the present study, an IDS nonsense mutation [c.928C > T (p.Gln310*)] was characterized in an extended Thai family. To the best of our knowledge, this variant has not been reported previously elsewhere. The mutation position at 79 nucleotides upstream from the exon 7-exon 8 junction point, reduces the polypeptide length from the initial 550 to 310 amino acids. This replacement of a glutamine codon with a stop codon may lead to unstable mRNA, subject to degradation by an NMD pathway. It has been reported that mutations that introduce a premature translation termination codon (PTC) at a position that is $>50-55$ nucleotides upstream of a splicing-generated exon-exon junction may trigger NMD $(30,31)$. Two previously described nonsense mutations in the IDS gene, namely p.Leu359* and p.Ser369*, exhibited a reduction of $30 \%$ in IDS mRNA level in the patient's samples in comparison with control samples (32). Those mutations were located $>50-55 \mathrm{bp}$ away from the exon-exon junction, whereas an increase of expression transcript was observed in p.Gln66*, in which the 
nonsense codon was $<50$ nucleotides upstream of the respective exon-exon junction point, which is in accordance with the NMD hypothesis (32). In the present study, the p.Gln310* transcript level was reduced to $27.2-37.1 \%$ of the mRNA level observed in the control samples, which is consistent with NMD.

The NMD mechanism is associated with eliminating mRNAs containing PTCs and thus limiting the synthesis of abnormal proteins (33). Several genes are known to produce aberrant PTC transcripts that fulfill the known criteria; however, some cases escape from NMD (34). The p.Gln310* mutation fits the requirements for NMD, in terms of the distance between the mutation position and the exon-exon junction. Although there have been previous reports of the existence of additional, identified (35) and unidentified (36) determinants that function to modulate NMD sensitivity, the p.Gln310* mutation appears to have fulfilled those criteria. Reduction of transcription product may lead to lower protein production, which may limit the amount of unfolded protein stress response and thereby modulate the disease. Ribosomal read-through has previously become a potential treatment strategy in patients with genetic diseases caused by PTC $(37,38)$. Development of compounds with increased read-through capacity and reduced toxicity remains challenging. These advanced treatments may potentially benefit the present patients who have a PTC mutation.

In conclusion, the present study has identified a novel nonsense mutation p.Gln310* in Thai patients with MPS II using molecular genetic analysis. The finding expands the spectrum of mutations in the IDS gene, which may improve genetic counseling and prenatal diagnosis, and improve understanding of the molecular mechanisms by which the mutation induces defects.

\section{Acknowledgements}

The present study was supported by the Chulabhorn Research Institute (Bangkok, Thailand).

\section{References}

1. Wilson PJ, Morris CP, Anson DS, Occhiodoro T, Bielicki J, Clements PR and Hopwood JJ: Hunter syndrome: Isolation of an iduronate-2-sulfatase cDNA clone and analysis of patient DNA. Proc Natl Acad Sci USA 87: 8531-8535, 1990.

2. Neufeld EF and Muenzer J: The mucopolysaccharidoses. In: The Metabolic \& Molecular Basis of Inherited Disease. Scriver CR, Beaudet AL, Sly WS and Valle D (eds). McGraw-Hill, New York, pp3421-3452, 2001.

3. Young ID, Harper PS, Newcombe RG and Archer IM: A clinical and genetic study of Hunter's syndrome. 2. Differences between the mild and severe forms. J Med Genet 19: 408-411, 1982.

4. Martin R, Beck M, Eng C, Guigliani R, Harmatz P, Muñoz V and Muenzer J: Recognition and diagnosis of Mucopolysaccharidosis II (Hunter syndrome). Pediatrics 121: e377-e386, 2008.

5. Bruni S, Loschi L, Incerti C, Gabrielli O and Coppa GV: Update on treatment of lysosomal storage diseases. Acta Myol 26: 87-92, 2007.

6. da Silva EM, Strufaldi MW, Andriolo RB and Silva LA: Enzyme replacement therapy with idursulfase for mucopolysaccharidosis type II (Hunter syndrome). Cochrane Database Syst Rev 11: CD008185, 2014.

7. Ochiai $\mathrm{T}$, Ito $\mathrm{K}$, Shichino $\mathrm{H}$, Chin $\mathrm{M}$ and Mugishima $\mathrm{H}$ : Ultrastructural findings of cutaneous nerves in patients with Hunter's syndrome following hematopoietic stem cell transplant. Med Mol Morphol 38: 118-122, 2005.
8. Ito K, Ochiai T, Suzuki H, Chin M, Shichino $\mathrm{H}$ and Mugishima $\mathrm{H}$ : The effect of haematopoietic stem cell transplant on papules with 'pebbly' appearance in Hunter's syndrome. Br J Dermatol 151: 207-211, 2004

9. Keeling KM, Xue X, Gunn G and Bedwell DM: Therapeutics based on stop codon readthrough. Annu Rev Genomics Hum Genet 15: 371-394, 2014.

10. Hong Y, Yu SS, Kim JM, Lee K, Na YS, Whitley CB, Sugimoto Y and Kim S: Construction of a high efficiency retroviral vector for gene therapy of Hunter's syndrome. J Gene Med 5: 18-29, 2003.

11. Rathmann M, Bunge S, Steglich C, Schwinger E and Gal A Evidence for an iduronate-sulfatase pseudogene near the functional Hunter syndrome gene in Xq27.3-q28. Hum Genet 95: 34-38, 1995.

12. Bondeson ML, Dahl N, Malmgren H, Kleijer WJ, Tönnesen T, Carlberg BM and Pettersson U: Inversion of the IDS gene resulting from recombination with IDS-related sequences is a common cause of the Hunter syndrome. Hum Mol Genet 4 : 615-621, 1995.

13. Lualdi S, Regis S, Di Rocco M, Corsolini F, Stroppiano M, Antuzzi D and Filocamo M: Characterization of iduronate-2-sulfatase gene-pseudogene recombinations in eight patients with Mucopolysaccharidosis type II revealed by a rapid PCR-based method. Hum Mutat 25: 491-497, 2005.

14. Human Gene Mutation Database (HGMD). http://www.hgmd. org/. Accessed June 1, 2016.

15. Keeratichamroen S, Cairns JR, Wattanasirichaigoon D, Wasant $P$, Ngiwsara L, Suwannarat P, Pangkanon S, Kuptanon J, Tanpaiboon P, Rujirawat T, et al: Molecular analysis of the iduronate-2-sulfatase gene in Thai patients with Hunter syndrome. J Inherit Metab Dis 31 (Suppl 2): S303-S311, 2008.

16. Charoenwattanasatien R, Cairns JR, Keeratichamroen S, Sawangareetrakul P, Tanpaiboon P, Wattanasirichaigoon D, Pangkanon S, Svasti J and Champattanachai V: Decreasing activity and altered protein processing of human iduronate-2-sulfatase mutations demonstrated by wxpression in $\operatorname{COS} 7$ cells. Biochem Genet 50: 990-997, 2002.

17. Mullen EM: Manual; Mullen Scales of Early Learning (AGS Edition Manual edition) NCS Pearson, Inc., Minneapolis, MN, 1995.

18. Voznyi YV, Keulemans JL and van Diggelen OP: A fluorimetric enzyme assay for the diagnosis of MPS II (Hunter disease). J Inherit Metab Dis 24: 675-680, 2001.

19. Livak KJ and Schmittgen TD: Analysis of relative gene expression data using real-time quantitative PCR and the 2(-Delta Delta C(T)) Method. Methods 25: 402-408, 2001.

20. Arnold K, Bordoli L, Kopp J and Schwede T: The Swiss-model workspace: A web-based environment for protein structure homology modeling. Bioinformatics 22: 195-201, 2006.

21. Bond CS, Clements PR, Ashby SJ, Collyer CA, Harrop SJ, Hopwood JJ and Guss JM: Structure of a human lysosomal sulfatase. Structure 5: 277-289, 1997.

22. Maquat LE: Nonsense-mediated mRNA decay in mammals. J Cell Sci 118: 1773-1776, 2005.

23. Millat G, Froissart R, Maire I and Bozon D: IDS transfer from overexpressing cells to IDS-deficient cells. Exp Cell Res 230: 362-367, 1997.

24. Lukatela G, Krauss N, Theis K, Selmer T, Gieselmann V, von Figura K and Saenger W: Crystal structure of human arylsulfatase A: The aldehyde function and the metal ion at the active site suggest a novel mechanism for sulfate ester hydrolysis. Biochemistry 37 : 3654-3664, 1998.

25. Hernandez-Guzman FG, Higashiyama T, Osawa Y and Ghosh D: Purification, characterization and crystallization of human placental estrone/dehydroepiandrosterone sulfatase, a membrane-bound enzyme of the endoplasmic reticulum. J Steroid Biochem Mol Biol 78: 441-450, 2001

26. Ghosh D: Human sulfatases: A structural perspective to catalysis. Cell Mol Life Sci 64: 2013-2022, 2007.

27. Parenti G, Meroni G and Ballabio A: The sulfatase gene family. Curr Opin Genet Dev 7: 386-391, 1997.

28. Wraith JE, Beck M, Giugliani R, Clarke J, Martin R and Muenzer J; HOS Investigators: Initial report from the Hunter outcome survey. Genet Med 10: 508-516, 2008.

29. Muenzer J, Beck M, Eng CM, Escolar ML, Giugliani R, Guffon NH, Harmatz P, Kamin W, Kampmann C, Koseoglu ST, et al: Multidisciplinary management of Hunter syndrome. Pediatrics 124: e1228-e1293, 2009.

30. Nagy E and Maquat LE: A rule for termination-codon position within intron-containing genes: When nonsense affects RNA abundance. Trends Biochem Sci 23: 198-199, 1998. 
31. Czapnski K, Ruiz-Echevarria MJ, González CI and Peltz SW: Should we kill the messenger? The role of the surveillance complex in translation termination and mRNA turnover. Bioessays 21: 685-696, 1999.

32. Lualdi S, Di-Rocco M, Corsolini F, Spada M, Bembi B, Cotugno G, Battini R, Stroppiano M, Gabriela PM and Filocamo M: Identification of nine new IDS alleles in mucopolysaccharidosis II. Quantitative evaluation by real-time RT-PCR of mRNAs sensitive to nonsense-mediated and nonstop decay mechanisms. Biochim Biophys Acta 1762: 478-484, 2006.

33. Wagner E and Lykke-Andersen J: mRNA surveillance: The perfect persist. J Cell Sci 115: 3033-3038, 2002.

34. Inácio A, Silva AL, Pinto J, Ji X, Morgado A, Almeida F, Faustino P, Lavina J, Liebhaber SA and Romão L: Nonsense mutations in close proximity to the initiation codon fail to trigger full nonsense-mediated mRNA decay. J Biol Chem 279: 32170-32180, 2004.
35. Denecke J, Kranz C, Kemming D, Koch HG and Marquardt T: An activated $5^{\prime}$ cryptic splice site in the human ALG3 gene generates a premature termination codon insensitive to nonsense-mediated mRNA decay in a new case of congenital disorder of glycosylation type Id (CDGId). Human Mutat 23: 477-486, 2004.

36. Danckwardt S, Neu-Yilik G, Thermann R, Frede U, Hentze MW and Kulozik AE: Abnormally spliced beta-globin mRNAs: A single point mutation generates transcripts sensitive and insensitive to nonsense-mediated mRNA decay. Blood 99: 1811-1816, 2002.

37. Wilschanski M, Yahav Y, Yaacov Y, Blau H, Bentur L, Rivlin J, Aviram M, Bdolah-Abram T, Bebok Z, Shushi L, et al: Gentamicin-induced correction of CFTR function in patients with cystic fibrosis and CFTR stop mutations. N Engl J Med 349: 1433-1441, 2003.

38. Lai CH, Chun HH, Nahas SA, Mitui M, Gamo KM, Du L and Gatti RA: Correction of ATM gene function by aminoglycoside-induced read-through of premature termination codons. Proc Natl Acad Sci USA 101: 15676-15681, 2004. 